\title{
MASTER
}

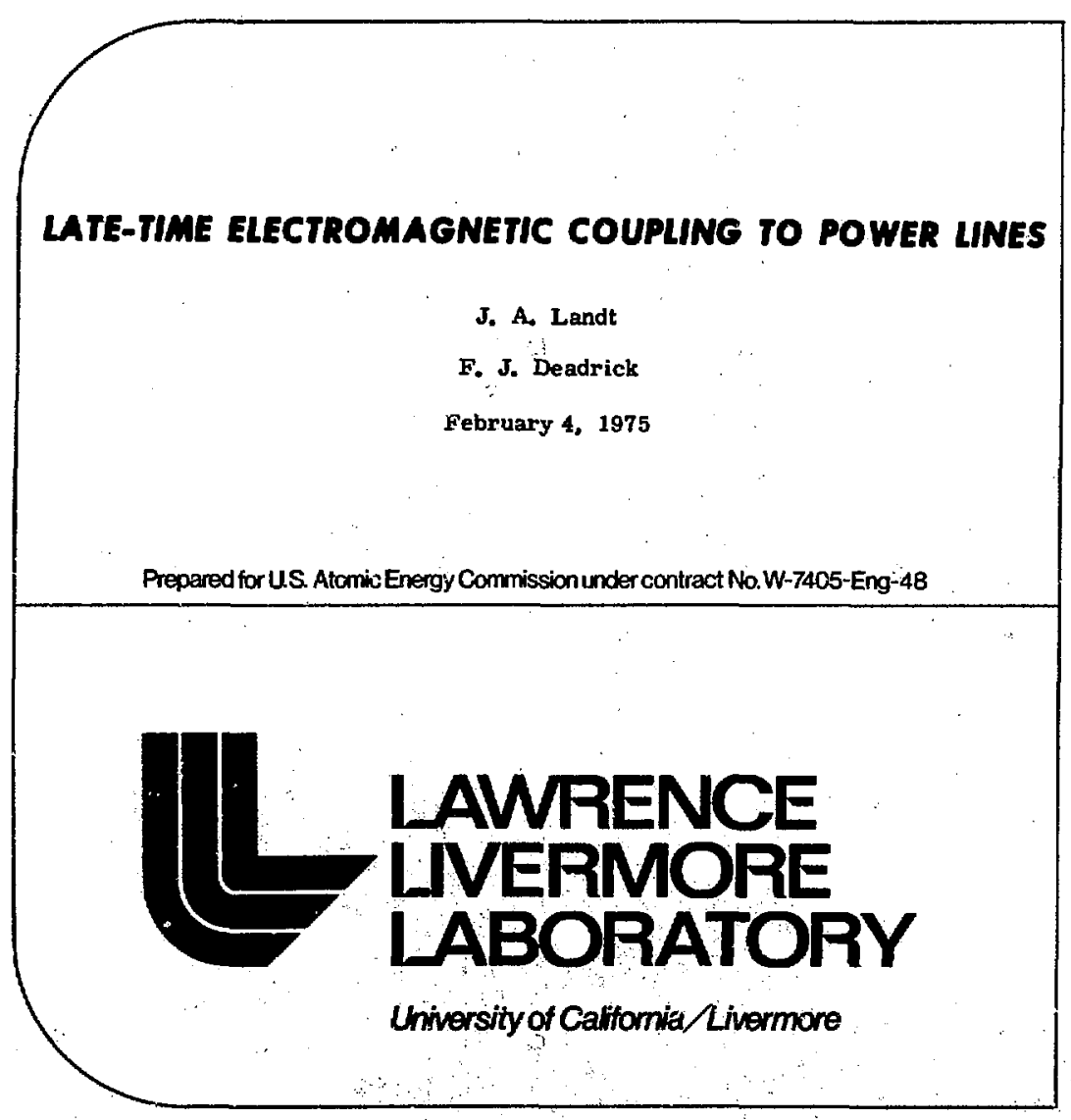




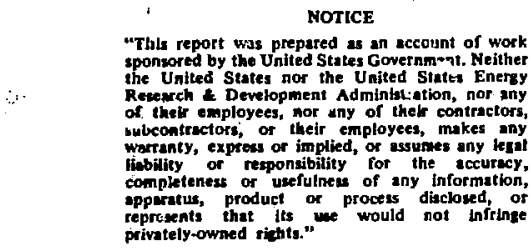

Printed in the United States of America Available from

National Technical Information Service

U. S. Department of Commerce 5285 Port Royal Road

Springfield, Virginia 22151

Price: Printed Copy $\$ *$; Microfiche $\$ 2.25$

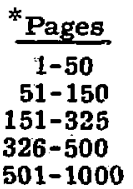

NTIS

Selling Price

$\$ 4.00$

$\$ 5.45$

$\$ 7.60$

$\$ 10.60$

501-1000

$\$ 13.60$ 
TID-4500, UC-38

Engineering and Equipment

\title{
近 \\ LAMFENCE INERMORE LABORATORY

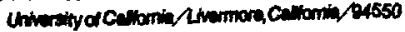

UCRL-51746

\section{LATE-TIME ELECTROMAGNETIC COUPLNG TO POWER LINES}

\author{
J. A, Landt
}

F. J. Deadrick

MS. date: February 4, 1975

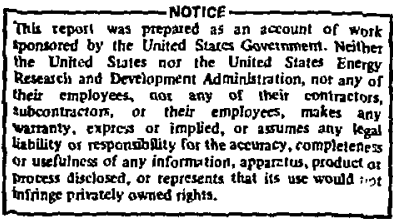




\title{
LATE-TIME ELECTROMAGNETIC COUPLING TO POWER LINES
}

\begin{abstract}
In this report we examine the problem of Nuclear EMP coupling to power lines, with particular emphasis on late-time response (times on the order of $1 \mathrm{~ms}$ ). We use a time-domain approach to find

the energy' collected by the power lines. Peak current estimates are obtained for power lines in iree-space, with catenary sag, and in proximity to perfect and finitely conducting grounds.
\end{abstract}

\section{Introduction}

Nuclear electromagnetic pulse (NEMP) coupling to power lines has received a great deal of attention from the EMP community. The Defense Nuclear Agency, Stanford Research Institute, Harry Diamond Laboratories, $\mathrm{R} \& \mathrm{D}$ Associates. and the Oak Ridge National Labrratory have studied EMP interaction whih power lines and EMP effects on power systems. The basic coupling mechanisms are understood and the effects of a real ground, termination loads, and some other parameters have been considered. The soonto-be published DNA handbook ${ }^{1}$ and other previous works are slanied toward prediction of "conventional" (high-altitude and surface-generated) EMP responses.

This report surmarizes our studies of coupling to power lines. The study emphasized late-time coupling (i. e., at times on the order of a millisecond). In addition, we devoted some effort to determining the importance of line droop and ohmic wire losses to EMP coupling to power lines. Also, attention was given to finding the energy (as well as current) collected by the lines. The energy collected has not been calculated in previous works. In the earlier studies, if the energy deliverable to a load was desired, the engineer had to perform some analysis on his own, and these calculations generally had to be performed for each new set of parameters. Recent studies have found, however, that under pulsed for transient) conditions, the total energy delivered to a load is less sensitive to load conditions than one would expect. (Peak currents, voltages, and decay rates can be quite sensitive to load conditions, however.)

The following results quantize the latetime coupling to power lines. We emphasize estimating the order of magnitude of the coupling. We also identify important parameters and summarize the present understanding of the coupling phenomenon. With this information, the reader can then make recommendations, in view of his requir ements, on the need for further analysis. 


\section{Results}

We decided to use techniques familiar to us raiher than adapt the methods of previous studies, "Exact" solutions were obtained using the computer code WT-MBA/LLL1B. ${ }^{2}$ This code determines the transient electromagnetic response of thin-wire structures through a momentmethod solution of an electric field integral equation formulated in the time domain. We modified an earlier technique $^{3}$ to obtain estimates of free-space responses. This technique parallels the fr.quency-domain results of Vance ${ }^{1}$ but allows us to produce estimates of transient waveforms more easily.

\section{TRANSMISSION LINE MODELS}

A power distribution system is very complex; we consider very fow details here. We assume that late-time coupling will probably be most important for long, uninterrupted lines, and we ignore the effects of substations, line terminations, lightning arrestors, line bends, etc. We consider only the response of straight wires, wires with catenary sag, and ground effects. We did not assess the effects of support towers, but since the towers are electrically insulated from the power lines, their effects on coupling should be minor.

A typical high-voltage power line consists of three conductors (for a threephase system) geparated by distances on the order of several meters. Each conductor is typically built of two cables held $0.4572 \mathrm{~m}$ ( $18 \mathrm{in}$ ) apart by steel spacers mounted every $76.2 \mathrm{~m}$ (250 it). Each cable is built of strands of aluminum and steel wire. The model chosen to study this structure was a single wire with a radius equal to the geometric mean of the cable diameter times the cable spacing. This makes the single wire respond electromagnetically the same as the cable pair. The refinement $r$ iscluding two or three conductors was not pursued. The resulting models (of various length) are shown over ground in Fig. 1. These same models were also used in free space. The angles $\theta, \phi$, and n. shown in Fig. 1, are used to describe the polarization and arrival direction of

(a)
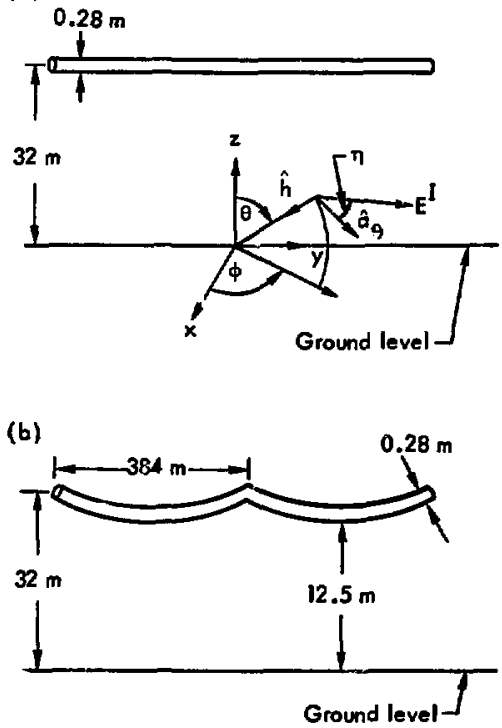

Fig. 1. Power line geometries. (a) Straight wire. (b) Catenary wire (two sections). 
the incident electromagnetic field. For exan.ple, when $\theta=\phi=0^{\circ}$ and $\eta=90^{\circ}$, we have broaoside incidence with the electric field parallel to the wire axis.

\section{FREQUENCY DOMAIN RESULTS}

Both frequency- and time-domain data are needed to form a clear picture of a system response. While these two domains are connected by the Fourier transform, it is difflcult to judge the response in one domain, given the response in the other domain. "whose interested in protecting bandlimited equipment find value in frequency-jomain resulis, while users of broadband equiprnent sensitive to peak currents or voltages find more use for time-domain data.

The current density excited on an infinite wire in free space and illuminated brcadside with an electric field aligned with the wire axes is 4

$$
J(\omega)=\frac{-2 E_{0}}{\omega \mu \pi a} \sum_{n=-\infty}^{\infty} \frac{i^{-n} e^{j \phi}}{H_{n}^{(2)}(k: a)}
$$

where

$$
\begin{aligned}
E_{0}= & \text { incident electric fie].d, in } \mathrm{V} / \mathrm{m} \\
\mathbf{k}= & 2 \pi / \lambda=\omega / \mathrm{c} \text { (freespace wave num- } \\
& \text { ber) } \\
\omega= & \text { frequency in radians/second, } \\
\mathrm{a}= & \text { wire radius, } \\
\mu= & \text { free space permeabillity, } \\
\mathrm{H}_{\mathbf{n}}^{(2)}= & \text { Hankel function of the second kind. }
\end{aligned}
$$
For low frequencies, where $2 \pi a<\lambda$, the total axial current can be approximated by

$$
I(w)=\frac{2 \pi E_{0}}{(j \omega \mu) \ln (\mathrm{ka})}
$$

which is essentially an integral relationship. This approximate integral relationship has been used to estimate the transient responses of wire structures. ${ }^{3}$

Equation (2) (or the appi oach of Vance ${ }^{1}$ ) can be used to form rough estimates of the frequency response of power lines. Presented here insteac are numerical calculations performed for a straight wire $5.4 \mathrm{~km}$ long in free space, and ilLuminated $45^{\circ}$ from broadside. Figure $2 \mathrm{a}$ shows the current observed at the center of the line resulting from the wave shown in Fig. 2b. The wave is expressed by $E^{I}(t)=\frac{d}{d t}\left\{\exp \left\{-a^{2}(t-t m)^{2}\right\}\right\}$ in $V / m$. The calculation was performed in the time domain with calculations terminated before reflections were observed from the far end of the wire. Figure $2 c$ shows the transfer function relating the current to the incident field. The calculations can be used to study the buildup of current on long wires in free space. The first positive current pulse is approximately proportional to the integral of the incident electric field, as expected. Reflections from the end of the wire account for the negative current pulse. The negative current pulse is not a duplicate of the first positive current pulse because (1) the reflection coefficient of the end of the wire is frequency-dependent, (2) radiation modifies the pulsc shape, and (3) the exciting electric field does not have the same phase relationship with the current pulses traveling opposite directions down the wire.

The first current pulse is "frozen" with the incident field. (This is not always the cas 2 , but is here because $\left.\int_{-\infty}^{\infty} E^{I}(t) d t=0.\right)$ The apparent phase velocity of the eleciric field along the wire is $c / s i n \theta$, while 

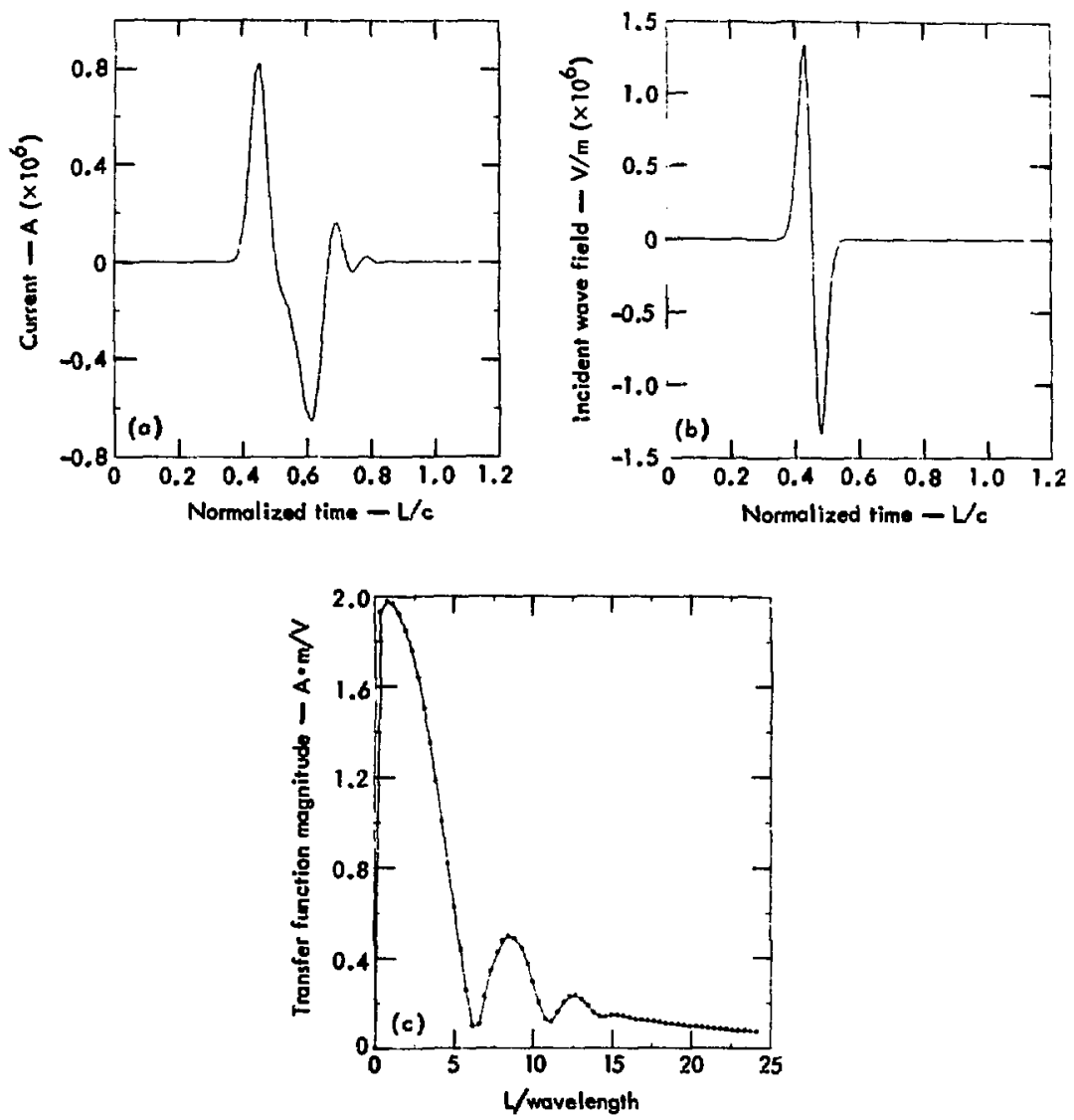

Fig. 2. Straight wire response in free space, $L=5,4 \mathrm{~km}$. (a) Current. (b) Incident field. (c) Specirum of the response.

the velocity of the negative current pulse is $c$, where $c$ is the speed of light, and $\theta$ is the angle of incidence of the electric field (and for $\phi=0^{\circ}, \eta \doteq 90^{\circ}$ ). Consequently, at a distanre $l$ from the end of the wile, the time difference between these two pulses will be

$$
\Delta T=\frac{l}{c}-\frac{l}{\operatorname{csin} \theta}=\frac{l}{c}(1-\sin \theta) .
$$

For the case of Fig. 2, $\theta=45^{\circ}, L=5.4 \mathrm{~km}$, and $\ell$ (the center of the line) $=2.7 \mathrm{~km}$, which yields $\Delta T=2.64 \mu$ sec. These two currents are of opposite sign, but of comparable shape. Consequently, a null 
should exist at a period equal to $\Delta T$, or at a normalized frequency $f_{n}$ :

$$
\begin{aligned}
f_{n} & =f \frac{2 \ell}{c} \\
& =\frac{1}{\Delta T} \frac{2 \ell}{c} \\
& \approx 6.8 .
\end{aligned}
$$

This accounts for the nulls observed in Fig. 2c. The frequency and strength or these nulls dep...td on load conditions and cbserver's position. The cuupling to the li'je was repeated, including a line resistance of $0.009 \Omega / 1000 \mathrm{ft}$. These calculations differ by less than one part in $10^{4}$ from those of Fig. 2, so they are r.ot presented here. Ohmic power losses do not appear to limit the cur rent buildup or affect late-time response significantly.

If we include the catenary wire droop, the coupling is affected, however, as shown in Fig. 3. The catenary wire geomeiry is shown in Fig. 1, and the same exciting field as used in Fig. 2 ap- plies here. Comparison of Figs. 2a and $3 a$ ind:cates that the main influence of the catenary droop is to introduce a late-time ringing at a wavelength equal to twice the high-point spacing (that is, the distance between the locations where the towers would be, if inclucied). This influcnce is small, however, as indicated by subtle c'langes in the transier function near this irequency.

Placing the wire $32 \mathrm{~m}$ above perfect growai, but using the same incident field as in Figs. 2 and 3 , resialts in large changes in the current. Figure 4 shows the transient current and the transfer function for the current. The perfect ground reflects the incident field and limits the current buildup. The coupling here is lower than the freespace coupling for all frequencies, but is most noticeable at low frequencies.

The response of the catenary line over perfect ground is shown in Fig. 5. Here the ringing at the wavelength equal to the
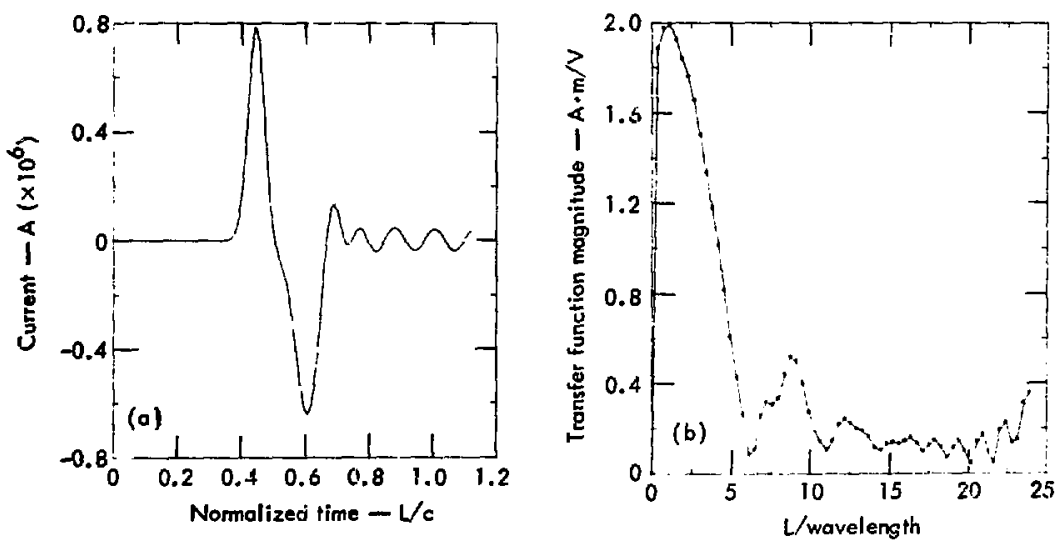

Fig. 3. Catenary wire response in free space, $L=5,4 \mathrm{~km}$. (a) Current. (b) Spectrum. 
tower spacing is more pronounced. The

ringing is shown at this frequency in

Fig. $5 a$, and is also indicated by the spike in the transfer function at this frequency (Fig. 5b)。

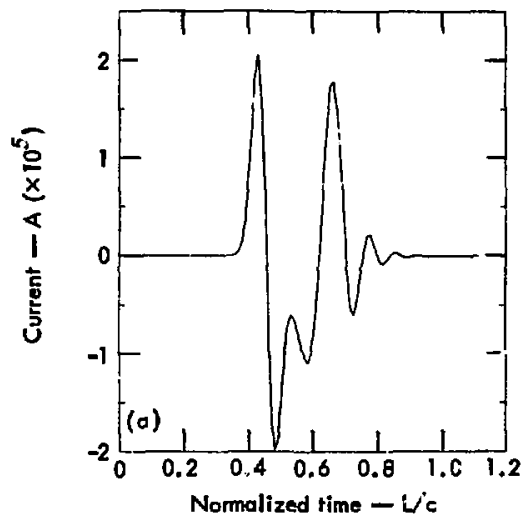

TIME DOMAIN RESULTS

The current induced at the center of an $L=5.4 \mathrm{~km}$ straight wire in free space is shown in Fig. 6 a for an incident electric

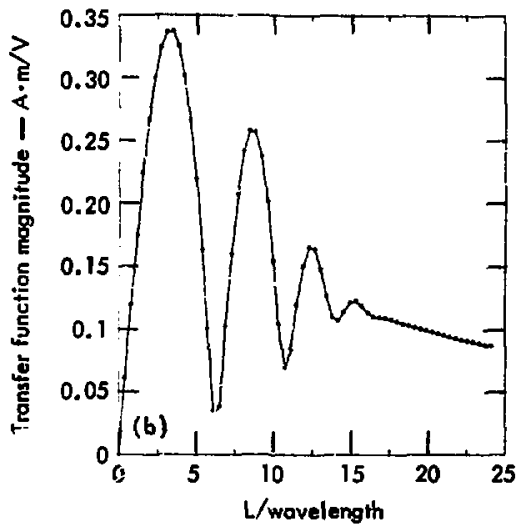

Fig. 4. Straight wire response over perfect ground, $\mathrm{J}=5.4 \mathrm{~km}$. (a) Current. (b) Spectrum.
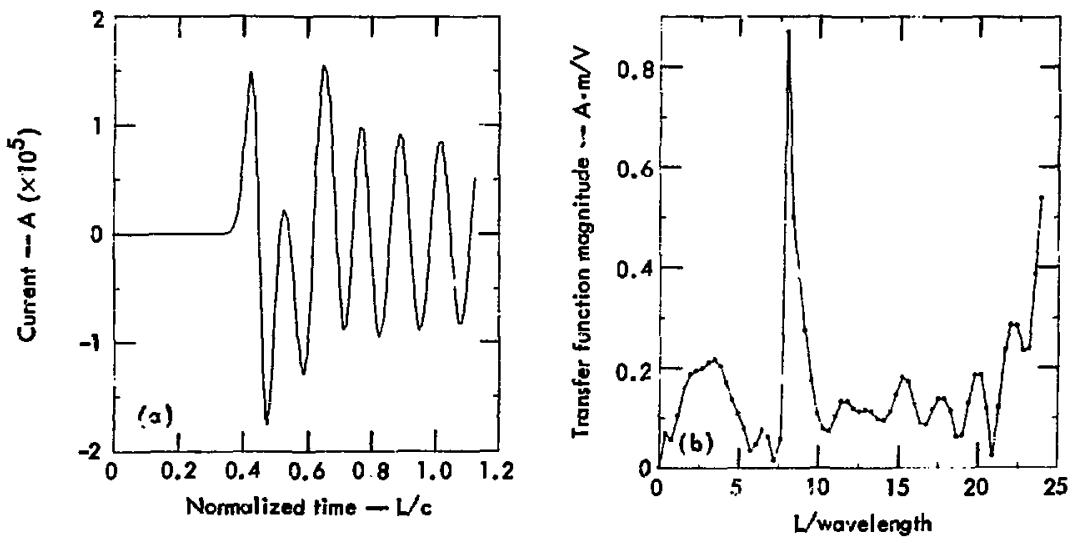

Fig. 5. Catenary wire response nver perfect ground, $L=5.4 \mathrm{~km}$. (a) Current. (b) Spectrum. 
field of $10^{3} \mathrm{~V} / \mathrm{m}$ incident $45^{\circ}$ from broadside. Calculatio' ts were terminated before reflections from the far end of the wire were observed. The current can be approximated as shown in Fig. 6b. The current will resemble this waveform any- where on the line for times before reflections from the far end are observed. At length $i$ down the wire, the times $t_{1}$ and $t_{2}$ are determined by the arrival of the incident field and the arrival of currents reflected from the end of the wire first
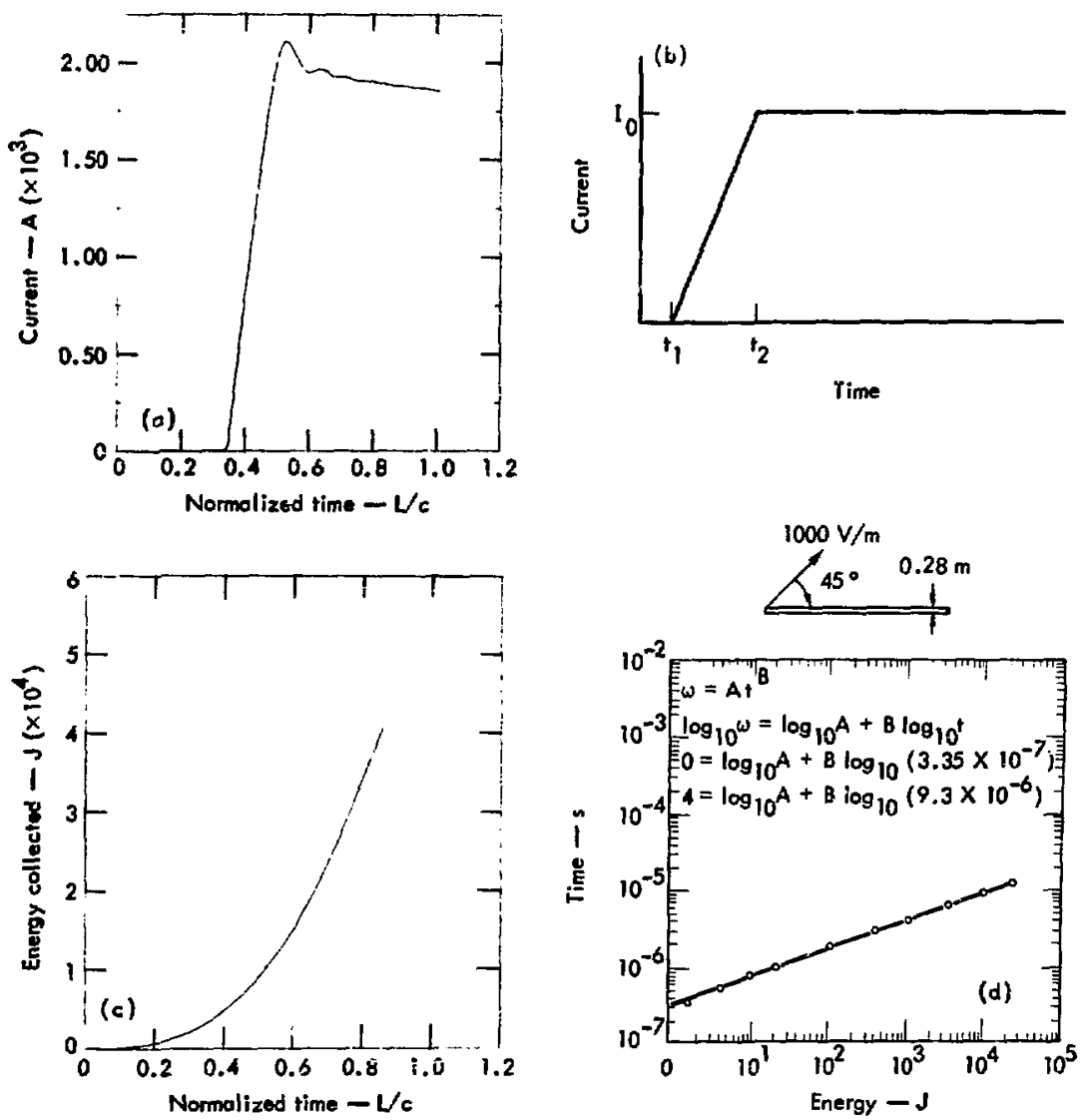

Fig. 6. Straight wire free space response to constant $1000 \mathrm{~V} / \mathrm{m}$ field, $\mathbf{L}=5.4 \mathrm{~km}$. (a) Current at center of line. (b) Approximate current response. (c) Energy collected. (d) Energy collected. 
illuminated by the incident wave. Using the notations adopted here

$$
t_{1}=\frac{\ell \sin \theta}{c}
$$

and

$$
t_{2}=\frac{\ell}{c} \text {. }
$$

The value of the peak current was found to be approximately proportional to $L$ and $1 / \cos \theta$. The early-time current for broadside incidence $\left(\theta=0^{\circ}\right)$ can be estimated using the scheme of Ref. 3.

The collected energy is shown in Figs. 6c and 6d. Apparently, the collected energy obeys the emperically derived equation (for $\$ 5^{\circ}$ from broadside).

$$
W(t)=8.8 t^{2.77} \text {, in } J \text {. }
$$

The induced current on a catenary wire in free space is shown in Fig. $7 \mathrm{a}$ and the collected energy in Fig. 7b. These curves are essentially the same as the straightvire curves.

The responses of the straight and catenary wires over perfect ground are shown in Figs, 8 and 9 for the same incident field of Figs. 6 and 7. The responses over ground are much different from the free space responses, In this case, the ground rellection limits the current increase, and the arrival of currents reflected from the first end of the wire forces the current to zero. Consequently, the current can be approximated by a pulse whose amplitude is independent of time or position, but whose duration varies as

$$
T=\frac{\ell}{c}(1-\sin \theta) \text {. }
$$

This current, with constant magnitude but linearly increasing pulse width, re-
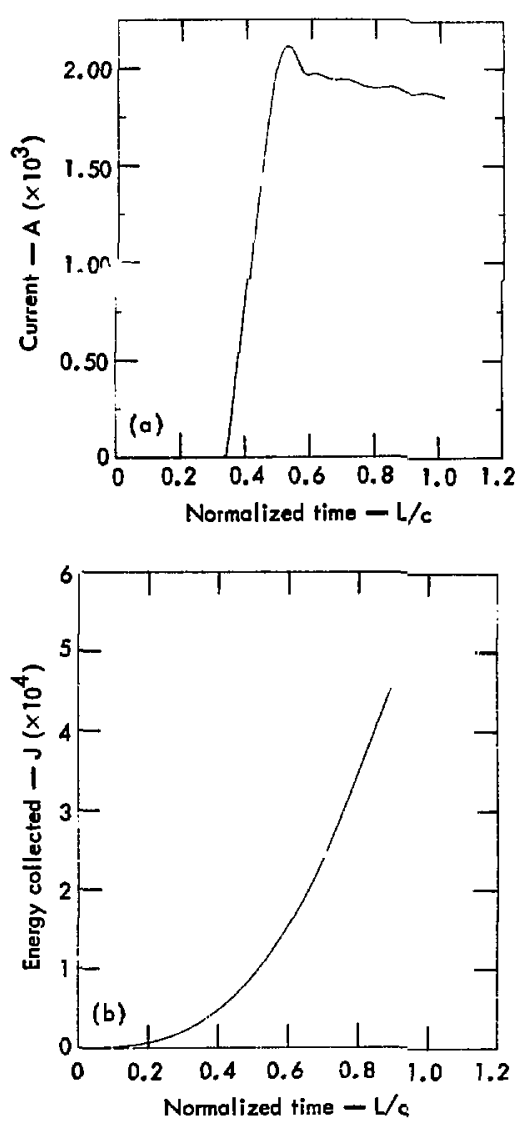

Fig. 7. Catenary wire response in free space to a constant $1 \mathrm{kV} / \mathrm{m}$ field, $I=5.4 \mathrm{~km}$, (a) Current.

(b) Energy collected.

sults in a linear increase with time for the energy collected. For the straight wire, the energy obeys the empirical equation

$$
W(t)=5.2 \times 10^{6} t \text {, in } J .
$$



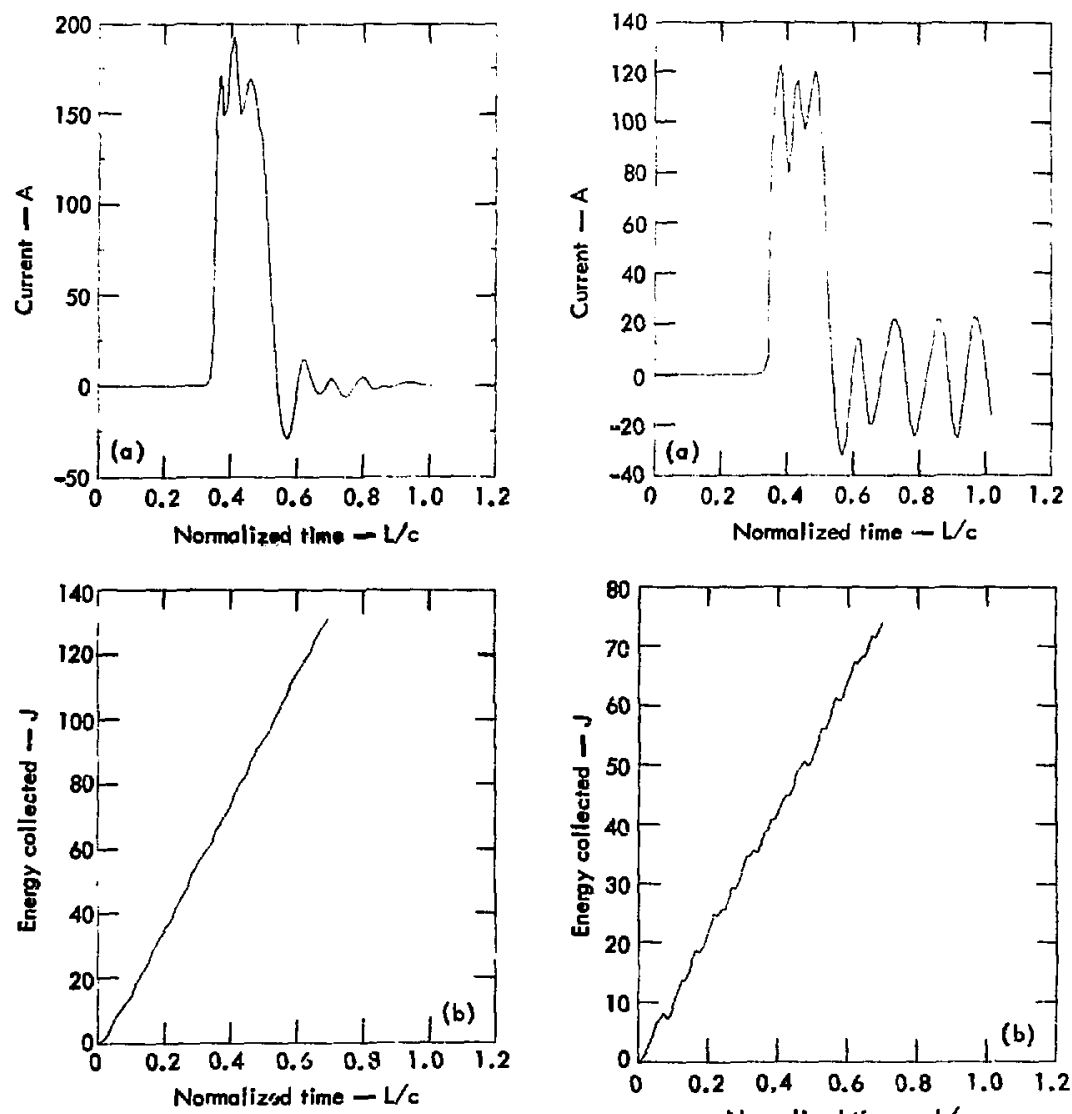

Fig. 8. Straight wire over perfect ground response to a constant $1 \mathrm{kV} / \mathrm{m}$ field, $L=5.4 \mathrm{~km}$, (a) Current. (b) Energy.

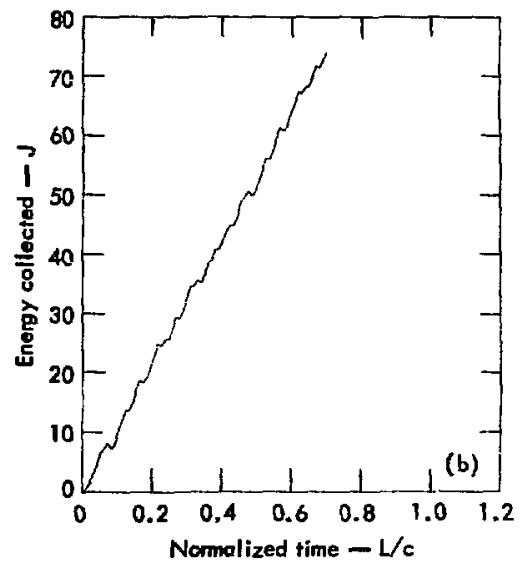

Fig. 9. Catenary wire ovez perfect ground response to a constant $1 \mathrm{kV} / \mathrm{m}$ field. (a) Current. (b) Energy.

The current and energy for the catenary case is slightly lower than the straightwire case because the catenary sag causes the average line height to be less than the $32-\mathrm{m}$ height of the straight wire. Thus the line is illuminated for a shorter time

before ground reflections are seen. Also notice that the catenary sag, in the presence of ground, causes a significant amount of ringing at a wavelength approximately equal to twice the tower spacing. 
For reference purposes, Figs. 10 and 11 show the catenary response to a two-term exponential wave of the form

$$
E^{I}(t)=E_{0}[\exp (-\alpha t)-\exp (-\beta t)]
$$
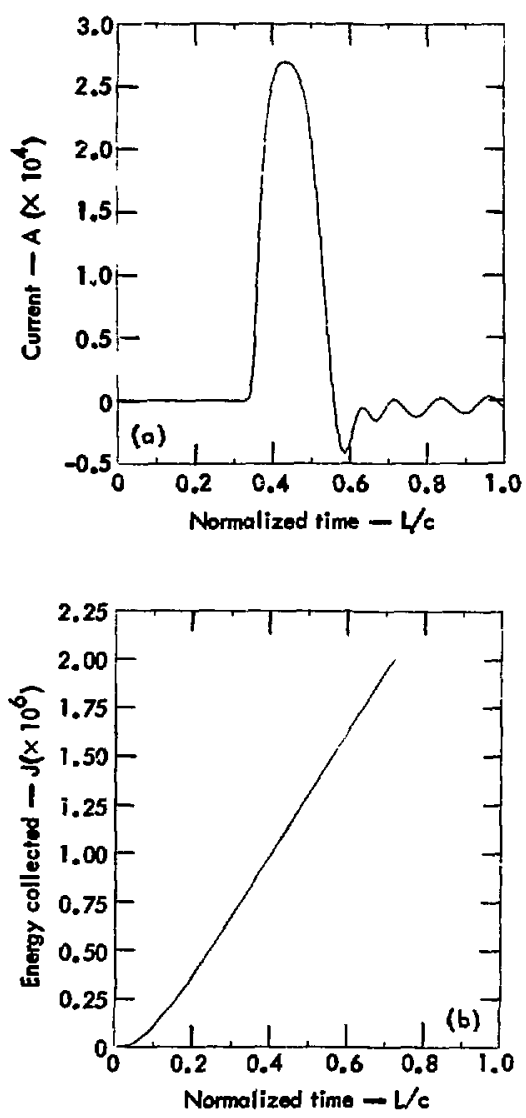

Fig. 10. Catenary wire in free space response to a two-term exponential wave, $L=5 \mathrm{~km}$. (a) Current, (b) Energy collected. for

$$
\begin{aligned}
\mathrm{E}_{0} & =1.05 \times 5 \times 10^{4} \mathrm{~V} / \mathrm{m}, \\
\alpha & =4.00 \times 10^{6}, \\
\beta & =4.76 \times 10^{8},
\end{aligned}
$$

which produces a peak field strength at $5 \times 10^{4} \mathrm{~V} / \mathrm{m}$. Figure 10 is the free-space response and Fig. 11 is the perfect-ground response. The effect of the ground is significant in this case, but not as large as the difference between these two cases using a $1000-\mathrm{V} / \mathrm{m}$ wave. These results are summarized in Table 1.

For the constant $1000-\mathrm{V} / \mathrm{m}$ incident field, the large difference in the functional dependence of energy on $t\left(i . e_{.}, t^{3}\right.$ vs $t$ ) between the free-space and perfect-ground results becomes very important at late times. Calculations show that by $0.5 \mathrm{msec}$, the free-space current has reached $1.8 \times 10^{5} \mathrm{~A}$ and the energy collected has reached $9.6 \times 10^{9} \mathrm{~J}$ for a straight wire in free space. For a straight wire over perfect ground, an estimation procedure ${ }^{3}$ shows that at $0.5 \mathrm{msec}$ the current is about $150 \mathrm{~A}$ and the energy has reached about $5 \times 10^{3} \mathrm{~J}$.

This large difference between the freespace and perfect-ground results for latetime coupling to a constant incident field indicates the need for including ground interactions more accurately.

\section{APPROXIMATE NONPERFECT GROUND RESULTS}

The clue for approximating the effects of a real ground are taken from Vance. ${ }^{1}$ 'r!e steps in the analysis are:

1. Find the electric field existing at the position of the wire, including ground reflection. 

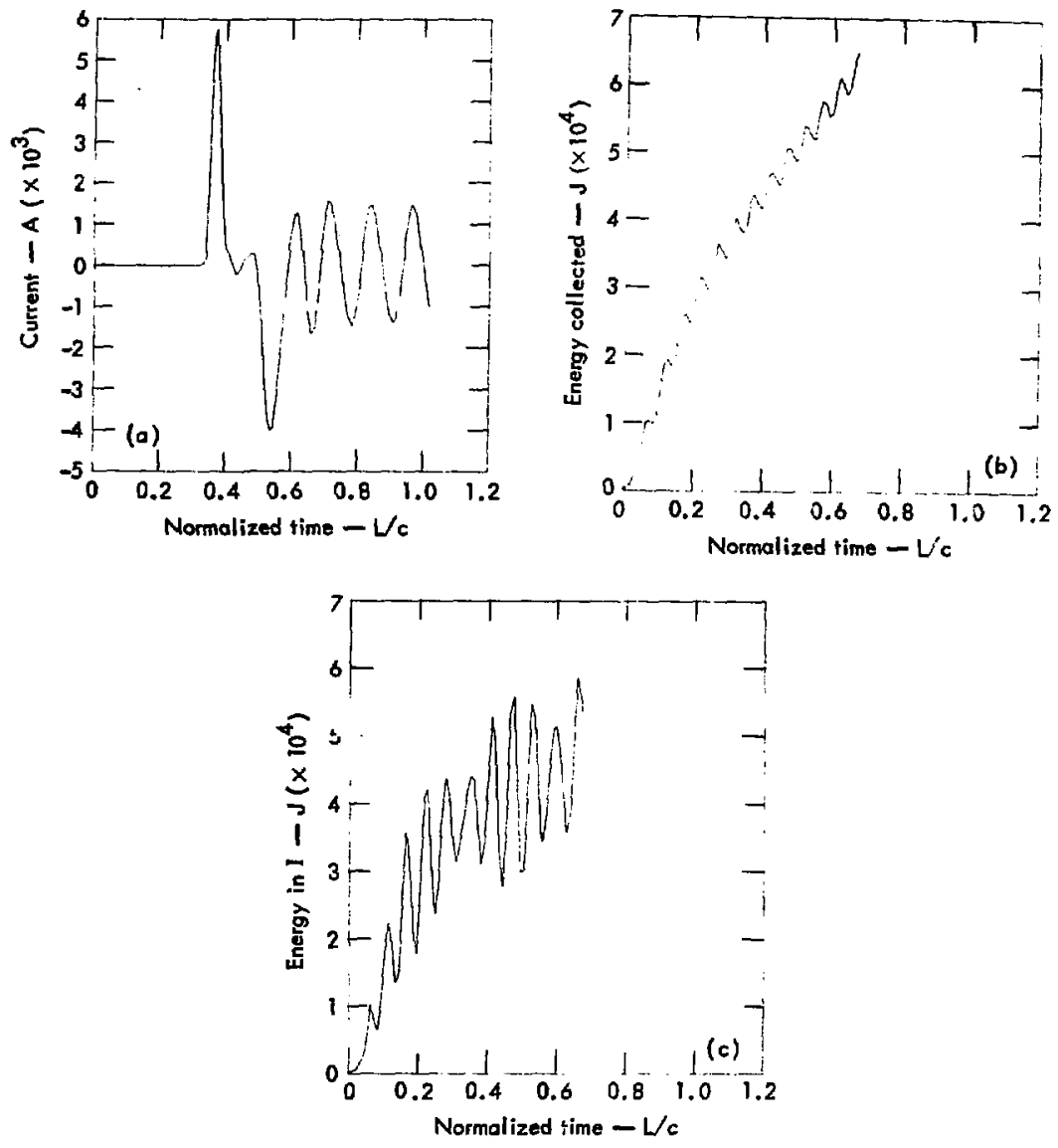

Fig. 11. Catenary wirs over perfect ground response to a two-term exponential wave, $\mathbf{L}=5.4 \mathrm{~km}$. (a) Current. (b) Energy collected. (c) Energy in the current.

2. Use transmission line theory (i. e.." now assuming perfect ground for the wire-ground interaction) to compute the induced current.

These steps are followed below for an incident electric field of $1000 \mathrm{~V} / \mathrm{m}$, lasting about $1 \mathrm{msec}$, for a straight wire.

\section{Ground Reflection of the Incirent Field}

An electric field may be uscomposed into two polarizations as shown in Fig. 12. Here the work of Ref. 5 is followed. For case (a), near the interface the total electric field parallel to the surface is 
Table 1. Summary of numerical solutions for catenary wire, field incident $45^{\circ}$ from broadside, current observed at $\ell=2.7 \mathrm{~km}$ down the wire.

\begin{tabular}{|c|c|c|c|c|}
\hline$E^{I}$ & $\begin{array}{c}\text { Peak cLerent } \\
\text { (A) }\end{array}$ & $\begin{array}{c}\text { Energy at } \\
t=\underset{(J)}{L} / 2 c\end{array}$ & $\begin{array}{l}\text { Functional } \\
\text { dependence } \\
\text { of energy }\end{array}$ & Notes \\
\hline $1000 \mathrm{~V} / \mathrm{m}$ & $2.1 \times 10^{3}$ & $1,0 \times 1{ }^{4}$ & $t^{3}$ & a \\
\hline $1000 \mathrm{~V} / \mathrm{m}$ & $1.2 \times 10^{2}$ & $5.2 \times 10^{1}$ & t & b \\
\hline 2-term & $2.7 \times 10^{4}$ & $1.3 \times 10^{6}$ & $t$ & a \\
\hline 2-term & $5.8 \times 10^{3}$ & $5.1 \times 10^{4}$ & $t$ & b \\
\hline
\end{tabular}

${ }^{\text {a}}$ Free space.

berfect ground.



(b)

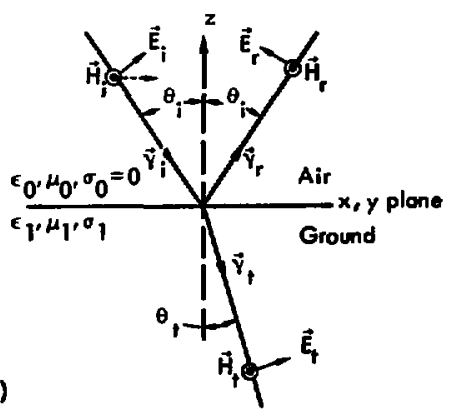

Fig. 12. Polarization of wave incident on ground. (a) Electric fleld parallel to ground. (b) Magnetic field parallel to ground.
$E=E^{I}(1+j) \sqrt{\frac{2}{p \epsilon_{r}}} \cos \theta$, in $V / m, p \gg 1$

where

$$
\begin{aligned}
\epsilon_{\mathbf{r}}= & \text { relative dielectric constant of } \\
& \text { the ground medium, } \\
p= & \frac{\sigma}{\omega \epsilon} \\
\sigma & =\text { ground concuctivity, mho/m } \\
\epsilon & =\text { absolute dielectric constant }
\end{aligned}
$$

For case (b) with magnetic field parallel to the ground,

$$
E=E^{I}(1-j) \sqrt{\frac{2}{p E_{r}}}, V / m \text {. }
$$

At a time on the order of $1 \mathrm{msec}$, we can use an equivalent frequency of $1 / 10^{-3} \mathrm{sec}$ $=1 \mathrm{kHz}$. For $\sigma=10^{-2} \mathrm{mho} m, \epsilon_{r}=25$, and $E^{I}=1000 \mathrm{~V} / \mathrm{m}$, case (b) yields

$$
E=4.7 \exp (-j \pi / 4), \mathrm{V} / \mathrm{m} \text {. }
$$

This field $(4.7 \mathrm{~V} / \mathrm{m})$ will be used to drive the transmission line.

\section{Coupling to a Transmission Line}

For the geometry of Fig. 13, the normal transmission line equations quantities are valid. The cheiacteristic Impedance ls

$$
z_{0}=\sqrt{\frac{g}{F}}
$$

where $\mathcal{E}=$ transmission line series inductance per meter and $\varphi=$ transmission line parallel capacitance per meter. The wave velocity is

$$
v=\frac{1}{\sqrt{h^{2}}}
$$

The only difference between the present problem and conventional transmiaston lines is the distributed source, which dives 


$$
\begin{aligned}
& \frac{\partial V}{\partial z}=E-\mathscr{P} \frac{\partial I}{\partial t}, \\
& \frac{\partial I}{\partial z}=-\mathscr{C} \frac{\partial V}{\partial t} .
\end{aligned}
$$

For the straight wire,

$$
\begin{aligned}
& \mathscr{S}=\frac{\mu}{2 \pi} \cosh ^{-1}\left(\frac{2 h}{d}\right), \\
& \mathscr{E}=2 \pi \epsilon / \cosh ^{-1}\left(\frac{2 h}{d}\right), \\
& Z_{0}=60 \cosh ^{-1}\left(\frac{2 h}{d}\right) \approx 60 \ln \left(\frac{4 h}{d}\right) \\
& v=c=3 \times 10^{8} \mathrm{~ms} .
\end{aligned}
$$

When $\mathrm{h}=32 \mathrm{~m}$ and $\mathrm{d}=0.28 \mathrm{~m}$,

$$
\begin{aligned}
\mathscr{Z} & =1.225 \times 10^{-6}, \text { in } \mathrm{H} / \mathrm{m} \\
\mathscr{S} & =9.095 \times 10^{-12}, \text { in } \mathrm{F} / \mathrm{m} \\
\mathrm{Z}_{0} & =367 \Omega \\
\mathrm{c} & =3 \times 10^{8} \mathrm{~m} / \mathrm{s} .
\end{aligned}
$$

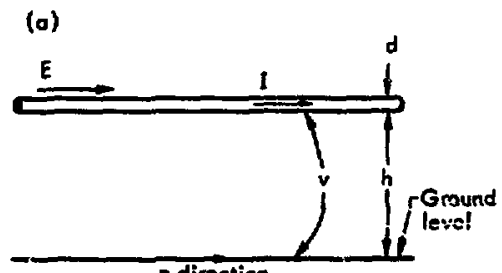

(b)



Fig. 13. Transtuitssion line model of distributed coupling to a poser line. (a) Power line. (b) incremental transmizsion lins model.
Application - Deyelopment of Current, Power, and Energy Responses

Case I - An infinite wire, broadside incidence.

Here,

$$
\frac{\partial l}{\partial z}=\frac{\partial V}{\partial z}=0
$$

so

$$
\begin{aligned}
\frac{\partial I}{\partial t} & =E / \mathscr{L} \\
I(t) & =\frac{E t}{\mathscr{L}}, \text { in } A .
\end{aligned}
$$

Per meter of line, the power and energy are

$$
\begin{aligned}
p(t) & =l(t) E(t) \\
& =\frac{E^{2} t}{\mathscr{S}}, \text { in } W / m \\
W(t) & =\int_{0}^{t} p(r) d r
\end{aligned}
$$

$$
w(t)=\frac{E^{2} t^{2}}{g^{2}} \text {, in } y / m
$$

If $t=0.5 \mathrm{~ms}$ and $s=300 \mathrm{~km}$, then

$1-1 \mathrm{v} 21 \mathrm{~A}$ and $W=0.77 \times 10^{5} \mathrm{~J}$.

Case 11 - Consider a semi-infinite line as shown in Fig. 14. Coupling to this geometry can be handled by the method of kef. 3. It can be shown that

$$
\begin{aligned}
& I(1, s)=\frac{\cos \theta t}{2 z_{0}}\left\{\frac{1}{1-\frac{\sin v}{t}} \int_{1-\frac{6}{c}}^{t-\frac{s \sin t}{c}} E_{1} r d t\right. \\
& +\left(\frac{1}{1+\sin \theta}\right) \int_{-\alpha}^{l-\frac{\sin \theta}{c}} 1 t r \gamma d \gamma
\end{aligned}
$$

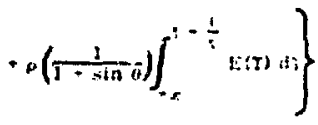


where

$$
\rho=\frac{Z_{0}-Z_{L}}{Z_{0}+Z_{L}}=\rho_{I}=\frac{I^{R}}{I^{I}} .
$$

$\rho$ is the current reflection coefficient, $Z_{0}$ is the transmission line characteristic impedance, and $Z_{L}$ is the termination load impedance. For $E(t)=E_{0} U(t)$ (i. e., a step function), the current becomes

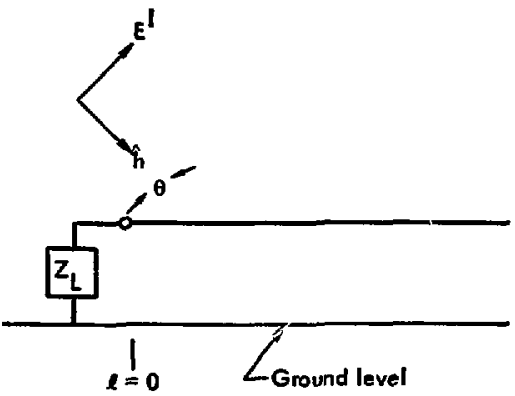

Fig. 14. Wave incident at terminated end of a long power line.

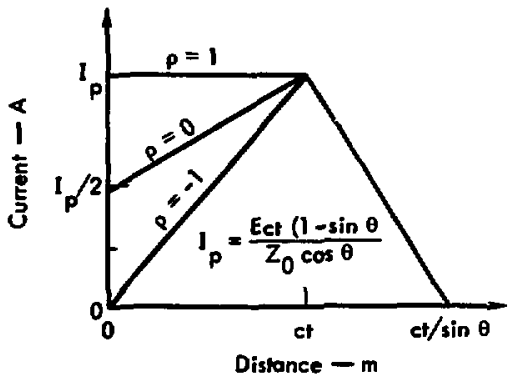

$$
I(t, l)= \begin{cases}0 & ; t<\frac{\ell \sin \theta}{c} \\ \frac{\mathrm{E}_{0}}{\mathrm{Z}_{0} \cos \theta}(c,-\ell \sin \theta) ; \frac{\ell \sin \theta}{c} \leq t \leq \frac{\ell}{c} \\ \frac{\mathrm{E}_{0}}{2 \mathrm{Z}_{0} \cos \theta}(\mathrm{ct}(1+\rho)+(1-\rho)\} ; t>\frac{\ell}{\mathrm{c}} .\end{cases}
$$

Figure 15 illustrates the behavior of the current at a given instant of time for various values of $\rho$. For $\rho=-1$,

$I(t)= \begin{cases}0 & ; \mathrm{t}<\frac{\ell \sin \theta}{\mathrm{c}} \\ \frac{\mathrm{E}_{0}(\mathrm{ct}-\ell \sin \theta)}{\mathrm{Z}_{0} \cos \theta} ; & : \frac{\ell \sin \theta}{\mathrm{c}} \leq \mathrm{t} \leq \frac{\ell}{\mathrm{c}} \\ \frac{\mathrm{E}_{0} \ell(1-\sin \theta)}{\mathrm{Z}_{0} \cos \theta} & ; \mathrm{t}>\frac{\ell}{\mathrm{c}}\end{cases}$

$p(t)=\frac{E^{2}(c t)^{2}}{2 Z_{0} \cos \theta}\left[\frac{1}{\sin \theta}-1\right]$, in $w$

$W(t)=\frac{E^{2} c^{2} t^{3}}{6 Z_{0} \cos \theta}\left[\frac{1}{\sin \theta}-1\right]$, in $J$.

\section{Case III - Broadside incidence on} wire of length $L, \rho=-1$ (an open circuit). Similarly, it can be shown in this case that

$I(t, \ell)=\left\{\begin{array}{l}\frac{\text { Ect }}{Z_{0}} ; 0 \leq t \leq \frac{\ell}{c} \text { and } \ell<\frac{L}{2} \\ \frac{E_{0} \ell}{Z_{0}} ; \frac{\ell}{c}<t \text { and } \ell<\frac{L}{2} .\end{array}\right.$

A similar set of expressions can be obtained for $\frac{L}{2}<\ell<L$. Also

$p(t)=\frac{E^{2} c t}{Z_{0}}[L-c t]$, in $w$

Fig. 15. Current for the line of Fig. 14. $W(t)=\frac{E^{2} c t^{2}}{Z_{0}}\left[\frac{L}{2}-\frac{c t}{3}\right]$, in J. 
Table 2. Coupling to wire over ground.

\begin{tabular}{|c|c|c|c|c|}
\hline Configuration & Apprcach & $\begin{array}{r}\text { Time } \\
\text { (ms) }\end{array}$ & $\begin{array}{c}\text { Peak } \\
\text { current } \\
\text { (A) }\end{array}$ & $\begin{array}{c}\text { Energy } \\
\text { collected } \\
\text { (J) }\end{array}$ \\
\hline $\begin{array}{l}300 \mathrm{~km} \text { of infinite line, } \\
\theta=0^{\circ}\end{array}$ & Case 1 & 0.5 & 1920 & $6.8 \times 10^{5}$ \\
\hline $\begin{array}{l}\text { semi-infinite line } \\
\quad \theta=45^{\circ}\end{array}$ & Case II & 0.71 & 1130 & $1.9 \times 10^{5}$ \\
\hline $\begin{array}{l}\text { open } 300-\mathrm{km} \text { line } \\
\theta=0^{\circ}\end{array}$ & Case III & 0.5 & 1920 & $4.5 \times 10^{5}$ \\
\hline
\end{tabular}

Application - Finite Transmission Line Over a Finite Ground

For the parameters

$$
\begin{aligned}
\sigma & =10^{-2} \mathrm{mho} \cdot \mathrm{m} \\
\epsilon_{\mathrm{r}} & =25 \\
\mathrm{~h} & =32 \mathrm{~m} \\
\mathrm{~d} & =0.28 \mathrm{~m} \\
E^{I} & =1000 \mathrm{~V} / \mathrm{m}
\end{aligned}
$$

$f=1 \mathrm{kHz}$ (i. e., period of $1 \mathrm{msec}$ )

$\mathbf{L}=300 \mathrm{~km}$ of line.

We determined earlier that $E=4.7 \mathrm{~V} / \mathrm{m}$, $Z_{0}=367 \Omega$, and that for $\theta=45^{\circ}$, the incident wave will hit the far end of the wire in $0.71 \mathrm{~ms}$.

Table 2 summarizes the coupling to a $300-\mathrm{km}$ wire over a real ground with the parameters given using the equations provided here.

\section{Comparison to High Altitude NEMP}

Table 3 summarizes coupling to wires as obtained in this study for lines of $300 \mathrm{~km}$ in length and on times on the order of: ms. From this table, it is evident that the upper and lower limits on latetime coupling place $\lambda$ by the two extremes of free space and perfect ground are too far apart to be useful. Consequently, the effects of a real ground must be included to obtain reasonable estimates of coupling. This was done here in an approximate fashion to obtain the value for real ground given in Table 3.

To explore the significance of the latetime coupling, two results for a more conventional two-term exponential NEMP are lncluded in Table 3. Direct comparison is difficult because for long lines the two-term exponential appears to be a "short" pulse, and although the apparent energy collected appears to be a linear function of time, the energy actually available is limited for the perfect-ground case (see Ref. 1). We did not evaluate this point fully, but Fig. 11c shows how the spatial integral of the square of the current behaves for the catenary line. For a normal transmission line, this integral multiplied by the characteristic impedance of the line yields the total 
Table 3. Summary of coupling.

\begin{tabular}{|c|c|c|c|}
\hline Configuration & Approach & $\begin{array}{l}\text { Peak current } \\
\text { (A) }\end{array}$ & $\begin{array}{l}\text { Energy } \\
\text { collected } \\
\text { (J) }\end{array}$ \\
\hline $\begin{array}{l}1000 \mathrm{~V} / \mathrm{m} \text { on a straight } \\
\text { wire in free space }\end{array}$ & $\begin{array}{l}\text { Numerical (computer } \\
\text { code) }\end{array}$ & $1.8 \times 10^{5}$ & $9.6 \times 10^{9}$ \\
\hline $\begin{array}{l}1000 \mathrm{~V} / \mathrm{m} \text { on a straight } \\
\text { wire } 32 \mathrm{~m} \text { above perfect } \\
\text { ground }\end{array}$ & Approximate (Ref. 3) & $1.5 \times 10^{2}$ & $4.9 \times 10^{3}$ \\
\hline $\begin{array}{l}1000 \mathrm{~V} / \mathrm{m} \text { on a straight } \\
\text { wire } 32 \mathrm{~m} \text { above a real } \\
\text { ground, open at ends }\end{array}$ & $\begin{array}{l}\text { Approximare scheme } \\
\text { discussed here }\end{array}$ & $1.9 \times 10^{3}$ & $4.5 \times 10^{5}$ \\
\hline $\begin{array}{l}\text { 2-term exponential } \\
5 \times 10^{4} \mathrm{~V} / \mathrm{m} 45^{\circ} \text { on } a \\
\text { catenary wire in free } \\
\text { space }\end{array}$ & $\begin{array}{l}\text { Numerical (extrapolation } \\
\text { to late times) }\end{array}$ & $2.7 \times 10^{4}$ & $1.3 \times 10^{8}$ \\
\hline $\begin{array}{l}\text { 2-term exponential, } \\
5 \times 10^{4} \mathrm{~V} / \mathrm{m} 45^{\circ} \text { on a } \\
\text { catenary wire over } \\
\text { perfect ground }\end{array}$ & $\begin{array}{l}\text { Numerical (extrapolation } \\
\text { to late times) }\end{array}$ & 5800 & $1.4 \times 10^{6}$ \\
\hline
\end{tabular}

energy available to a matched load. Notice that before the incident field has reached the end of the line (it was incident at $45^{\circ}$ from broadside), the energy in the current appears to become limited. The total energy collected by this time is about $3 \times 10^{4} \mathrm{~J}$. The energy available in the case of a constant-magnitude incident field joes not become llmited in this fashion: 1.e., the value of $4.5 \times 10^{5} \mathrm{~J}$ given in Table 3 is a reasonable eatimate of the eneray actually available to a load, The work of vance ${ }^{l}$ can also be uaed to estimate the enerify availeble at the end of a semi-infinite line over real ground for high-altitude NEMP. Using the nolation of Vance for the sume arrival Alrection considered here then $\theta=45 \%$ $4=0^{\circ}$ and $\varphi=45$, The open circuit voltage using E.q. $(2-17)$ of Vance is

$$
\begin{aligned}
& V_{o c}(t)=\left\{\begin{array}{l}
E_{0} c r D\left(1-e^{-t / x_{1}}\right) ; 0 \leq t \leq t_{0} . \\
E_{0} \operatorname{cr} \cap\left\{\left(e^{t_{0} / T}-1\right) e^{-t / r}\right.
\end{array}\right.
\end{aligned}
$$

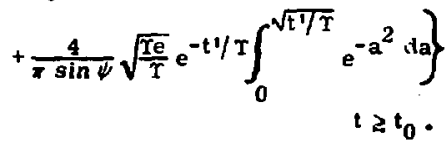

Here $T$ is the parsinster of a single terin NEMP of the form:

$$
E^{I}(t)=E_{0} e^{-t / r}
$$

and is typically $0.25 \times 10^{-6} \mathrm{~g}$. Also,

$$
\begin{aligned}
& t '=t-t_{0}, \\
& t_{0}=2 \frac{h}{c} \sin \psi, \\
& h=\text { line height, } \\
& T e=\sigma / \epsilon_{0} .
\end{aligned}
$$


The voltage across a matched load is $1 / 2 \mathrm{~V}_{\text {oc }}$, the power delivered is $1 / 4\left(\mathrm{~V}_{\mathrm{oc}}\right)^{2} / \mathrm{Z}_{0}$, and the total energy delivered, $w$, is $\int_{0}^{\infty} 1 / 4\left(\mathrm{~V}_{\mathrm{oc}}\right)^{2} / \mathrm{z}_{0} \mathrm{dt}$. Figure 16 shows a reasonable approximation to $\mathrm{Eq},(2-17)$ of Vance for the parameters of interest here.

This open-circuit voltage will then deliver an energy of $5100 \mathrm{~J}$ and a peak current of $6100 \mathrm{~A}$ to a matched load. This is a factor of six smaller than the preliminary numerical calculatio.ts performed for c: - c.enary line and a factor of 100 smaller than preliminary estimates

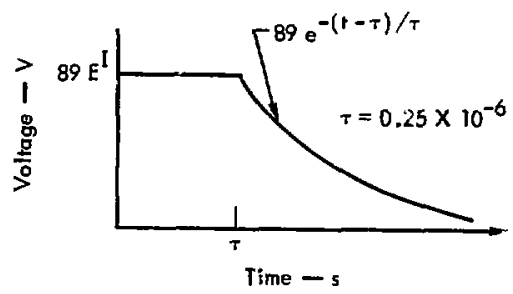

Fig. 16. Approximate open circuit voltage.

for late-time coupling to a $300-\mathrm{km}$ line by a $1-\mathrm{kV} / \mathrm{m}$ field.

\section{Summary and Fecommendations}

In this study we have determined that the effects of a real (lossy) ground must be considered to obtain reasonably accurate estimates of late-time coupling to power lines. A comprehensive calculation of this coupling has not yet been undertaken, and would be the next step if this study were to be continued. Preliminary calculations have shown, however, that the energy coupled to a power line by a l-kV/m constant field may exceed highaltitude NEMP coupling by one or two orders of magnitude (10 or 100 times) by late times (i. e., in about $1 \mathrm{~ms}$ ). The $1 \mathrm{kV} / \mathrm{m}$ induced currents will represent only about a $100 \%$ overage in the design current capacity of a typical highvoltage power line, but the spectruna of this current is much different rrom the current induced by high-altitude NEMP.

We have also determined that the catenary wire sag between support towers increases coupling at a wavelength equal to twice the tower spacing. The line response is seen to ring at this frequency, but the total energy collected and peak currents induced are approximately the same as those found for straight wires. We also found that ohmic wire loss plays an insignificant role in the coupling.

It should also be pointed out that one must take extreme care in making estimates of coupling to $\mathrm{lc} . \mathrm{gg}$ power lines. A glance through the tables of this report will show energies ranging all the way from 5000 to $10^{10} \mathrm{~J}$. Such a spread is unacceptable and under.inas the need for considering ground effects.

Last, it should be mentioned that high energies, peak voltages, and peak currents are not always required to upset a system. For example, a long-distance communication system has been upset by a geomagnetic disturbance that created an electric field of $5 \mathrm{~V} / \mathrm{km}$. The resulting ground fault currents caused system upset. 6 


\section{References}

1. E. F. Vance, Electromagnetic Pulse Handbook for Electric Power Systems, Defense Nuclear Agency Rept. 3466F (197!).

2. J. A. Landt, E. K, Miller, and M. VanBlaricum, WT-MBA/LLL1B: A Computer Program for the Time-Domain Electromagnetic Response of Thin-Wire Structures, Lawrence Livermore Laboratory, Rept. UCRL -51585 (1974).

3. J. A, Landt, Peak Current Estimates: Cylinders in Free Space With Extenslons to Other Structures, Lawrence Livermore Laboratory, Rept. UCID-1647 1 (1974).

4. R. F. Harrington, Tlme-Harmonic Electromagnetic Fields, (McGraw-Hill, New York, N. $Y_{0}, 1961$ ), pp 23z-234.

5. R, J. Lytle and D, L. Lager, Electromagnetic Propagation, Transmission, Reflection, and Refractic Equations and Numerical Results, Lawrence Livermore Laboratory, Rept. UCRL-51245 (1972).

6. C. W. Anderson, L. J. Lanzerotti, and C. G. MacLennan, "Outage of the L4 System and the Geomagnetic Disturbances of 4 August 1972," The Bell System Technical Journal, 53, No. 9, 1817 (Nov. 1974). 